\title{
Creative Commons
}

\section{Creative Commons License Deed}

Atribución-NoComercial-SinDerivadas 2.5 Colombia (CC BY-NC-ND 2.5 CO)

This is a human-readable summary of (and not a substitute for) the license.

Advertencia

\section{Usted es libre para:}

Compartir - copiar y redistribuir el material en cualquier medio o formato

El licenciante no puede revocar estas libertades en tanto usted siga los términos de la licencia

\section{Bajo los siguientes términos:}

Atribución - Usted debe darle crédito a esta obra de manera adecuada, proporcionando un enlace a la licencia, e indicando si se han realizado cambios. Puede hacerlo en cualquier forma razonable, pero no de forma tal que sugiera que usted o su uso tienen el apoyo del licenciante. NoComercial - Usted no puede hacer uso del material con fines comerciales.

Sin Derivar - Si usted mezcla, transforma o crea nuevo material a partir de esta obra, usted no podrá distribuir el material modificado.

No hay restricciones adicionales - Usted no puede aplicar términos legales ni medidas tecnológicas que restrinjan legalmente a otros hacer cualquier uso permitido por la licencia.

\section{Aviso:}

Usted no tiene que cumplir con la licencia para los materiales en el dominio público o cuando su uso esté permitido por una excepción o limitación aplicable.

No se entregan garantías. La licencia podría no entregarle todos los permisos que necesita para el uso que tenga previsto. Por ejemplo, otros derechos como relativos a publicidad, privacidad, o derechos morales pueden limitar la forma en que utilice el material. 


\title{
PENALIZACIÓN DEL MALTRATO ANIMAL EN COLOMBIA
}

\section{Daniela Contreras Rojas ${ }^{1}$}

\section{RESUMEN}

La Ley 1774 de 2016 estableció la protección penal de la vida la integridad física y emocional de los animales, con base en dos presupuestos: primero, la eliminación de la consideración de los animales como 'cosas' para reconocerlos como 'seres sintientes', y segundo, la tipificación del maltrato animal (muerte o lesiones graves) como delito.

\begin{abstract}
ABSTRAC
The law 1774 of 2016 set the criminal protection of life, physical and emotional integrity of animals, based on two points: The first one, elimination to considered animals like 'goods' for recognize them like 'sentient beings', and the second one, the new penal type Cruelty to Animals (death or several hurts) like crime.
\end{abstract}

\section{PALABRAS CLAVE}

Protección, Animales, Seres Sintientes, Maltrato Animal, Penalización.

\section{KEY WORDS}

Protections, Animals, Sentient Beings, Cruelty to Animals, Penalty.

\footnotetext{
${ }^{1}$ Estudiante de Derecho y Aspirante a Grado de la Universidad Católica de Colombia
} 


\section{SUMARIO}

* Introducción

1. Evolución de la protección de los animales
1.1. Marco Legal
1.2. Marco Jurisprudencial

2. Derecho Penal colombiano en los delitos contra los animales.

3. Estudio de la Ley 1774 de 2016

4. Primeros casos de investigaciones penales por maltrato animal

* Conclusiones

* Referencias bibliográficas 


\section{INTRODUCCIÓN}

El reconocimiento actual en Colombia de los animales como seres sintientes ha sido un largo proceso. Hoy en día ya podemos concebir el maltrato animal como un delito en nuestro país y los animales se han convertido en sujetos de especial protección por la ley. En un país con alto nivel de violencia como Colombia, es fundamental encontrar el medio idóneo para reducir al máximo cualquier tipo de maltrato hacia estos seres. Esta es la motivación para que en el presente artículo reflexivo se busque dar una respuesta al problema jurídico que se plantea: ¿Cómo protege el Derecho Penal colombiano a los animales?

Como objetivo general se busca examinar el alcance dogmático de los tipos penales y establecer si la penalización del maltrato animal en Colombia, entendiendo el maltrato como muerte o lesión grave en la salud o integridad física y emocional, es uno de los medios adecuados para proteger a los animales.

En primera instancia se realizará un recuento histórico, desde una perspectiva legal y jurisprudencial, que mostrará la evolución de la protección de los animales y los significativos cambios a través del tiempo en torno a la problemática animal a nivel nacional.

Se examinará, en términos generales, como el Derecho Penal colombiano entra a ser parte fundamental de la protección de los animales, para así poder fijar una posición frente al problema jurídico que aquí nos atañe.

Posteriormente, se realizará un estudio dogmático de la Ley 1774 de 2016 'Por medio de la cual se modifican el código civil, la ley 84 de 1989, el código penal, el código de procedimiento penal y se dictan otras disposiciones', para examinar el alcance normativo penal de la protección de los animales, los agravantes y las excepciones contempladas allí, que permitirá fijar una posición sobre el problema. 
Con el estudio dogmático penal de los artículos de la Ley 1774 de 2016 y los casos que se expondrán, se podrá de alguna manera establecer si la intención del legislador de proteger a los animales, puede llegar a ser una realidad o si presenta dificultades para materializarla por existir vacíos e insuficiencia normativa. Es evidente que la finalidad del legislador en la penalización del maltrato animal, no fue únicamente la de reprimir a quienes cometieran los delitos estipulados en la ley, sino que también contempló una finalidad restaurativa.

Lo más importante debe ser la formación cultural a las personas para que exista un verdadero cambio en el comportamiento frente a los animales, en pro de que éstos sean considerarlos por todos como seres que sienten y así mismo sufren afectaciones emocionales cuando son maltratados, generando una concientización en la sociedad.

La inclusión de un título especial en el Código Penal Colombiano, la modulación y/o erradicación legal de la 'cosificación' de los animales en el Código Civil y el aumento en las multas contenidas en la Ley 84 de 1989, quiebra en gran medida la brecha especista que se había impuesto desde hace tantos años y que pocos se atrevían a romper. 


\section{Evolución de la protección de los animales}

\subsection{Marco Legal}

Como se afirma por Cubides, "Hablar del derecho animal, el bienestar animal o de los derechos de los animales ya no es una excentricidad traída de latitudes lejanas. Cada día crece el número de organizaciones no gubernamentales que le apuestan a esa causa, mientras que la legislación en los diversos rincones del mundo no se queda atrás" (Cubides, 2014, párr. 1).

Antes de iniciar, es importante aclarar que en Colombia no podemos hablar de manera estricta de 'Derechos de los Animales', entendidos estos como "El conjunto de normas legales encaminadas a proteger los derechos fundamentales de los seres vivos no humanos, entiéndase animales; dichas normas legales han de ser creadas, implementadas y ejercidas por los órganos estatales de cada sociedad." (Morales, 2003, p. 28), pues este reconocimiento aún no se ha logrado en el país.

El inglés Garner plantea:

"Desde el siglo XIX se ha convertido en norma la aceptación de la posición moral de los animales, pero los intereses de los humanos deben prevalecer sobre la base que nosotros tenemos nivel de racionalidad que nos permite ser agentes morales. Muchos nombres claves en la teoría política liberal contemporánea - John Rawls como el más notable - mientras aceptan que los animales tienen algo de valor moral, aún insisten en que no son 10 suficientemente morales para ser, junto con los humanos, como receptores de justicia" (Garner, 2005, p.10)².

\footnotetext{
2 Texto original en inglés, traducción personal.
} 
Lo anterior es un pensamiento muy común que se sigue sosteniendo aún en pleno siglo XXI en países como Colombia, no obstante que, en 1978, la ONU y la Unesco aprobaron la Declaración Universal de los Derechos de los Animales, donde se declara que los animales poseen el derecho a la vida, al respeto, a la protección, a vivir en su propio ambiente y a reproducirse, entre otros, tanto que deben ser defendidos legalmente. (Cubides, 2014, párr. 3). Es por ello que aquí nos enfocaremos en la protección a los animales como seres sintientes, siendo esta la categoría que adquirieron con la nueva ley aquí objeto de estudio.

Para empezar, realizaremos un recorrido cronológico con las más relevantes Leyes, Decretos y Resoluciones que con anterioridad y después de la Constitución de 1991, han realizado regulaciones sobre los animales en distintos aspectos.

En primera medida debemos hablar de nuestra Constitución Política de 1991. Esta no consagra de manera explícita una protección a los animales. Si se quiere de alguna manera hablar de la protección constitucional de éstos, se debe recurrir a una especie de analogía que permita incluir a los animales dentro del Título II Capítulo III 'De los derechos colectivos y del ambiente', específicamente en artículos como el 79 que consagra:

"Todas las personas tienen derecho a gozar de un ambiente sano. La ley garantizará la participación de la comunidad en las decisiones que puedan afectarlo.

Es deber del Estado proteger la diversidad e integridad del ambiente, conservar las áreas de especial importancia ecológica y fomentar la educación para el logro de estos fines" (Subrayado fuera de texto original)

Podemos notar que aún no es suficiente el nivel de protección que otorga la Constitución a los animales. Si la pretensión es reconocerlos como seres de 
especial protección, ésta debería consagrarse de manera directa y específica para lograr un reconocimiento mucho más efectivo.

Si se permite hacer un ejercicio de Derecho Comparado, Alemania en el año 2002, tras un debate en Cámara baja aprobó modificar el Artículo 20 de la Ley Fundamental de la República Federal de Alemania con el fin de dar a la protección de los animales un rango constitucional, incluyendo la 'Protección de los fundamentos naturales de la vida y de los animales'. (Krauthausen, 2002).

Esta decisión fue fundamental en Alemania para el reconocimiento de los animales como seres sujetos de derecho. La protección a los animales se convirtió en un objetivo más del Estado, dándole así una dimensión jurídica que le permitiese entrar a sopesarse con los demás derechos fundamentales, sin ser uno de manera estricta, en caso de eventuales ponderaciones.

Otro ejemplo que podemos tener de un país que eleva el derecho de los animales a nivel constitucional, es Suiza con su Constitución de 1999 y su enmienda de 2002. Aunque sus argumentos son de índole religioso, contempla un respeto hacia todo lo que integra la Creación, desde el preámbulo de la misma. Esto permite crear una fuerza vinculante que somete a los jueces a dar cumplimiento a esos mandatos de manera obligatoria, así como a cualquier otra autoridad dentro del Estado. (Cárdenas y Fajardo, 2007)

Por otro lado, nuestro país ha tenido una serie de Leyes, Decretos y Resoluciones, que se han expedido a medida del tiempo según las diferentes necesidades. A continuación veremos las más relevantes:

* Ley 5 de 1972, Reglamentada por el Decreto 497 de 1973, 'Por la cual se provee a la fundación y funcionamiento de Juntas Defensoras de Animales': 
Esta fue la primera Ley existente en nuestro país que contenía temas relacionados con la protección a los animales. En esta Ley se destacaron las campañas educativas y culturales orientadas al respeto y amor por los animales, con el fin de evitar actos de crueldad o maltrato hacia ellos. El Decreto 497 de 1973 permitió ampliar y aclarar un poco la función de las Juntas Defensoras de Animales.

Es importante citar un fragmento de la exposición de motivos del proyecto de ley 99 de 1965:

"Esta idea que a muchos ha de parecer extraña, tiende a lograr el laudable objetivo de enseñar a las gentes a dar buen trato, alimento, bebida, descanso, sombra, drogas, vacunas curativas y preventivas; (...) cuidado del bienestar y mejoramiento de todas las razas animales" (Perilla, 1965, p. 187. Como se citó en Cárdenas y Fajardo, 2007.)

El anterior texto nos permite apreciar cómo desde la época anterior a la Constitución de 1991 el legislador pretendió que las personas tuvieran en cuenta las condiciones mínimas para el bienestar de los animales. Lastimosamente el éxito de esta Ley, entre otros factores, dependía mucho del compromiso de la ciudadanía y de las entidades públicas y éste simplemente no se cumplió como se esperaba.

\section{* Ley 9 de 1979 'Por la cual se dictan Medidas Sanitarias':}

Esta Ley, que cuenta con varios decretos reglamentarios, se crea con el fin de dictar normas generales y procedimientos en torno a medidas sanitarias. En varios artículos, especialmente los relacionados con la industria cárnica, la crianza, los establecimientos de comercio de animales, entre otros, hace mención a los animales. 
Al hacer lectura de ellos, se puede evidenciar que en esta ley se consideraba a los animales como objetos al servicio del hombre, lo que genera incompatibilidades con las posiciones que hoy en día se defienden.

Ley 84 de 1989, 'Por la cual se adopta el Estatuto Nacional de Protección de los Animales y se crean unas contravenciones y se regula lo referente a su procedimiento y competencia'.

Tal vez uno de los mayores avances en la protección a los animales se obtuvo con esta ley, ya que fue el primer paso al reconocimiento formal de los animales como seres sintientes, pues pretendía la protección de éstos contra el sufrimiento y el dolor, causados directa o indirectamente por el hombre, como bien lo consagró en su Artículo 1.

Esta ley, conformada por 10 Capítulos, regula temas como deberes para con los animales, penas y agravantes, procedimiento en el sacrificio de animales, experimentación e investigación, transporte, caza y pesca, y las competencias de las entidades facultadas para conocer este tipo de casos.

La ley buscó: "a) Prevenir y tratar el dolor y el sufrimiento de los animales; b) promover la salud y el bienestar de los animales, asegurándoles higiene, sanidad y condiciones apropiadas de existencia; c) erradicar y sancionar el maltrato y los actos de crueldad para con los animales; d) desarrollar programas educativos a través de medios de comunicación del Estado y de los establecimientos de educación social y privados, que promuevan el respeto y el cuidado de los animales; e) desarrollar medidas efectivas para la preservación de la fauna silvestre". (Artículo 2).

Sin embargo, la misma dejó de ser eficaz a medida del paso del tiempo porque que las penas y multas incluidas en el texto eran completamente irrisorias y el 
desconocimiento de la misma era completamente notorio, tanto en la ciudadanía como en las entidades públicas, lo que llevó a esta ley a no tener aplicabilidad, es decir, a convertirla en lo que comúnmente se conoce como "letra muerta".

Esta ineficacia llevó a que numerosos congresistas, a través de los años, presentaran proyectos de ley con el fin de derogarla, pero ninguno cumplía las expectativas para convertirse en Ley de la República.

Adicionalmente hay que tener en cuenta que el nivel de concientización no era el mismo que vivimos hoy en día, por lo que la importancia que la sociedad le daba a este tipo de reconocimiento con respecto a los animales era mínima y en muchas ocasiones podía tornarse incluso nugatorio, lo que hacía más difícil que se cumpliera con lo pretendido por la Ley.

* Resolución 11101 de 1999, derogada por la Resolución 02601 de 2003, que reglamentó lo relacionado con la tenencia de perros para la prestación del servicio de Vigilancia y Seguridad Privada, contenida en el artículo 50 parágrafo único del Decreto 356 de 1994, que consagraba las condiciones que debían tener los animales que prestaran estos servicios y se especificaba el cuidado de éstos a una persona determinada.

De estas Resoluciones se pueden inferir dos cosas. En primer lugar, en la lectura del texto efectivamente se evidencia una protección a la vida, salud y bienestar de los animales que prestan este tipo de servicio. El artículo 22 de esta última resolución agregó operativos de control, en cualquier tiempo, por la Superintendencia de Vigilancia y Seguridad Privada y los organismos especializados en la materia. Además, facultó a la Sociedad Protectora de Animales para la realización de esos controles e incluyó la denuncia por parte de los ciudadanos que presenciaran o tuvieran conocimiento sobre maltratos hacia 
estos animales (esta denuncia vista desde un punto netamente disciplinario y no con implicaciones penales).

En segundo lugar, también podemos evidenciar una calificación a los caninos como meros objetos para la prestación de esos servicios, lo que implica una 'cosificación' de estos animales. La crítica reiterada es que ningún animal debería estar destinado a ningún tipo de trabajo, salvo que sea estrictamente necesario, verbigracia animales de compañía para personas con alguna discapacidad, toda vez que ellos no tienen la capacidad de discernir entre querer realizarlo o no, sumándose al hecho de que en la actualidad podemos contar con variedad de recursos científicos y tecnológicos como apoyo a estos trabajos, sumado a ello, por supuesto, el recurso humano.

A pesar de esa posición, no se debe desconocer la importancia de estas Resoluciones, pues plantea condiciones enfocadas al mayor bienestar posible a los animales que prestan estos servicios.

* Acuerdo 79 de 2003, 'Por el cual se expide el Código de Policía de Bogotá D.C.'

Dentro de este articulado encontramos la protección de los animales en el Libro Segundo 'Deberes y comportamientos para la convivencia ciudadana', Título III 'Para la conservación de la salud pública', Capítulo 4 'En la protección y cuidado de los animales', artículo 34; y Título V 'Para conservar y proteger el ambiente' Capítulo 4 'La fauna y la flora silvestres' artículos 62 al 64.

En el Capítulo 4 del Título III, se encuentran 10 numerales que consagran deberes para con los animales, junto con un listado de parámetros mínimos que garantizan la salud y bienestar de los mismos. La inobservancia de lo estipulado en esos numerales, da lugar a las medidas correctivas estipuladas en el Libro 
Tercero, Título III, artículo 164, del mismo Código, como la amonestación en público y compromiso de cumplir las reglas de convivencia ciudadana; asistencia a programas pedagógicos de convivencia ciudadana; multas; entre otras.

El Capítulo 4 del Título V, contempla que la protección y conversación tanto de la fauna como de la flora silvestre, son de interés general, por ser recursos del patrimonio ambiental, social y cultural del país, como puede leerse en su artículo 62. Contempla además comportamientos que favorecen a la conversación de las especies silvestres (artículo 63) y el apoyo a las organizaciones que participen en la conservación y protección del ambiente (artículo 64). Las inobservancias en los comportamientos consagrados en el artículo 63, también están sujetas a las mismas medidas correctivas del artículo 164 anteriormente mencionado.

Adicional a lo anterior, este Código también contiene otros artículos que regulan ciertos temas con relación a los animales como el artículo 12 numeral 9, en relación con las razas de perros consideradas potencialmente peligrosas; el artículo 30 numeral 5, en relación con el sacrificio de animales para consumo humano; el artículo 33 numeral 21, en relación con sobre venta de especies prohibidas por autoridades ambientales, entre otros.

Este código consagró importantes acercamientos a un reconocimiento especial de los animales. No obstante, no era suficiente que el Maltrato Animal se quedara en las medidas correctivas de este código. Era necesaria la trascendencia de éste, por su clara ineficacia en la aplicabilidad.

Ley 1453 de 2011 'Por medio de la cual se reforma el Código Penal, el Código de Procedimiento Penal, el Código de Infancia y Adolescencia, las reglas sobre extinción de dominio y se dictan otras disposiciones en materia de seguridad'. 
Esta ley incrementó las penas y multas de los delitos contra los recursos naturales y el medio ambiente. Estos eran los únicos delitos que estaban contemplados en el Código Penal contra la fauna colombiana. Además, adicionó el artículo 330A 'Manejo ilícito de especies exóticas' y modificó los artículos 334 y 335 'Experimentación ilegal con especies, agentes biológicos o bioquímicos' e 'llícita actividad de pesca', respectivamente.

Podemos darnos cuenta que el legislador no fue completamente indiferente a tipificar delitos en que los sujetos motivo de protección fueran los animales, aunque los supuestos de hecho fueron previstos con fines de la conservación del medio ambiente.

* Decreto 40 de 2013 'Por el cual se implementa el Programa de Sustitución de Vehículos de Tracción Animal en Bogotá D.C. y se dictan otras disposiciones.' en concordancia con el Decreto 178 de 2012 'Por el cual se establecen medidas relacionadas con la sustitución de vehículos de tracción animal'.

El Decreto 178 de 2012, en cumplimiento del artículo 98 de la Ley 769 de 2002 'Por la cual se expide el Código Nacional de Tránsito Terrestre y se dictan otras disposiciones' y de la Sentencia C-355 de 2003, autorizó "la sustitución de vehículos de tracción animal por vehículos automotores debidamente homologados para carga, para facilitar e incentivar el desarrollo y promoción de actividades alternativas y sustitutivas para los conductores de vehículos de tracción animal" (Artículo 1).

Consagró además la forma en que debían realizarse las sustituciones y encargó para ello a las alcaldías municipales y distritales en coordinación con las autoridades de Transporte y Tránsito. 
Posterior a ello, en enero de 2013 se expide el Decreto 40, donde finalmente se erradican por completo los Vehículos de Tracción Animal en la ciudad de Bogotá D.C. El objetivo no fue distinto al de promover actividades alternativas y sustitutivas para los conductores de los Vehículos de Tracción Animal en la ciudad de Bogotá D.C., contemplando los beneficios del programa y las condiciones para acceder al mismo.

Este Decreto tuvo en cuenta las dos caras de la problemática. Por un lado, las personas que vivían de ello por no contar con otro tipo de posibilidad en ingresos. Por otro lado, los desafortunados equinos que habían sido sometidos a la tortuosa labor, contemplando alternativas de protección para ellos como cuidados, tratamiento médico e incluso la adopción bajo rigurosas condiciones, en pro de su estabilidad.

A pesar de haber sido un importante avance para la ciudad, por hacerse realidad lo que varias administraciones habían prometido, desafortunadamente aún existen ciudades en nuestro país que utilizan los Vehículos de Tracción Animal, en especial para fines turísticos, amparados en la excepción del Parágrafo 1 del artículo 98 que establece: "Quedan exceptuados de la anterior medida los vehículos de tracción animal utilizados para fines turísticos, de acuerdo a las normas que expedirá al respecto el Ministerio de Transporte".

* Ley 1638 de 2013 'Por medio de la cual se prohíbe el uso de animales silvestres, ya sean nativos o exóticos, en circos fijos e itinerantes'

Esta Ley tuvo gran acogida en la ciudadanía, toda vez que prohibió la utilización de animales silvestres para los espectáculos circenses en todo el territorio nacional. Sin embargo, la utilización de animales domésticos en estos espectáculos no fue contemplada dentro de esta ley. 
Si bien es cierto que fue un paso importante para la protección de los animales, la ley se quedó algo corta al no incluir dentro de la prohibición a todos los animales, toda vez que los efectos negativos causados por el confinamiento y el exceso de trabajo, pueden afectar a cualquier animal, sumándole a ello los malos tratos que la mayoría de los 'entrenadores' les dan.

No obstante, el legislador planteó la Ley en esos términos, bajo el argumento de que los animales domésticos, verbigracia perros o gatos, no constituían un problema de seguridad ni de salubridad, como sí los animales silvestres y exóticos, en términos del senador Juan Córdoba.

Para entender un poco la intención del legislador, parece pertinente citar la posición de una organización de derechos de los animales canadiense, que se pronunció con una posición similar frente al tema:

"Es prácticamente imposible proporcionar una calidad de vida en los circos para animales salvajes por naturaleza. Física, psicológica $y$ comportamentalmente tienen necesidades complejas, y esas condiciones de vida serán siempre inadecuadas. [...]

Ese sufrimiento puede fácilmente terminar. Eliminar los actos que involucren animales significará simplemente incrementar los actos con humanos. Los circos con presentaciones solo humanas son populares $y$ exitosos [...]" (Animal Alliance of Canada. Como se citó en Tamara, 1999) ${ }^{3}$

Ley 1774 de 2016 'Por medio de la cual se modifican el Código Civil, la Ley 84 de 1989, el Código Penal, El Código de Procedimiento Penal y se dictan otras disposiciones'.

\footnotetext{
${ }^{3}$ Texto original en inglés, traducción personal.
} 
Por último, en el año 2015, el Senador Juan Carlos Lozada, junto con la 'bancada animalista' decide presentar el Proyecto de Ley 087, que posteriormente se convirtió en Proyecto de ley 172, con el fin de modificar el Código Civil, la Ley 84 de 1989, el Código Penal y el Código de Procedimiento Penal, para dar a los animales la denominación de seres sintientes y de especial protección, además de tipificar como punible el Maltrato Animal. Este proyecto de Ley fue aprobado en diciembre del año 2015 y sancionado el 06 de enero de 2016.

\subsection{Marco Jurisprudencial}

Existen varios pronunciamientos judiciales mediante tutelas y sentencias que han aportado a los debates sobre la protección de los animales. A continuación se exponen las más relevantes sentencias de constitucionalidad existentes hasta el momento, algunas de las cuales están directamente relacionadas con leyes enunciadas en el Marco Legal de este artículo.

\section{Sentencia C-692 de 2003 Magistrado Ponente Marco Gerardo Monroy Cabra}

La Corte Constitucional resuelve acá el problema jurídico sobre la legitimidad de impedir a los menores de edad ser titulares del derecho de propiedad de razas caninas consideradas como potencialmente peligrosas.

La Corte sostiene que existe una limitación al derecho de dominio injustificado, concluyendo que los menores de edad pueden ser titulares de perros denominados potencialmente peligrosos, sin ejercer la tenencia. Por lo que declara inexequible el Artículo 108-G de la Ley 746 de 2002, donde decía que los menores de edad no pueden ser propietarios de los canes descritos en los artículos 108-E y 108-F de la misma ley. 
Además, declaró la inexequiblidad del apartado 'en las vías públicas, lugares abiertos al público y en las zonas comunes de edificios o conjuntos residenciales', contenida en el artículo 108-H, porque no permite una protección completa a los menores de edad sobre la tenencia de los caninos.

Esta sentencia gira en torno al bienestar de los menores de edad y los derechos de propiedad y tenencia de las personas, y no se preocupa de manera directa por los caninos, pero es importante para el tema que nos atañe, toda vez que nos encontramos frente a una discriminación respecto a ciertas razas de perros, discriminación que afecta eventualmente la Protección Animal

El concepto de 'potencialmente peligrosos', se entendería como un concepto jurídico indeterminado con tintes peyorativos, toda vez que se califica a ciertas razas de perros de manera automática como peligrosas, por el solo hecho de pertenecer a la misma. Se juzga al canino de manera instantánea sin considerar otros factores influyentes y determinantes, como lo es la crianza y formación que los seres humanos le impartan.

Dentro de la revista 'Muy Interesante' de España, encontramos un artículo titulado 'No hay razas de perro peligrosas, sino dueños peligrosos' donde referencian un estudio publicado en la revista 'Applied Animal Behaviour Science' que asegura que: "la conducta agresiva del perro se debe en mayor medida a la conducta agresiva del dueño". (Como se citó en Martínez, s.f, párr. 1)

Los científicos realizaron encuestas a 4.000 dueños de perros de razas consideradas 'potencialmente peligrosas', para analizar la conducta de éstos en diferentes contextos, las cuales determinaron lo siguiente:

"El carácter del propietario era determinante en el grado de agresividad de su mascota, en detrimento de la raza a la que pertenecía. 
Según los datos recabados, los perros entrenados con castigo y refuerzo negativo tenían el doble de probabilidades de gruñir o morder a los extraños y tres veces más probabilidades de ser hostiles hacia los miembros de la familia". (Como se citó en Martínez, s.f, párr. 2 y 3)

Lo que nos lleva a concluir que, si bien sí existen características de las razas que pueden influir (verbigracia las mandíbulas más grandes y fuertes en comparación con otras razas), los dueños, así como la crianza que éstos dan y el trato de terceros hacia los caninos, son factores determinantes. La crítica es dirigida a lo preocupante de que se impongan prejuicios a estos caninos, puesto que esa predisposición conlleva en su mayoría a destinos fatales para los mismos.

Para cerrar este tema, resulta importante la opinión de la Dra. Rachel Casey, Veterinaria científico-conductista de la Universidad de Bristol, quién realizó un estudio sobre el tema aquí tratado en el que concluyó:

"Los dueños de perros y miembros del público deben ser conscientes de que cualquier perro podría mostrar agresión si está ansioso o se siente amenazado, incluso cuando nunca antes lo ha demostrado. Por otro lado, los perros que han mostrado signos agresivos en una situación no son necesariamente "peligrosos" cuando en otros contextos - una consideración importante en la evaluación de los animales, tales como en centros de reubicación". (Casey et al, 2014, p.59). ${ }^{4}$

\section{Sentencia C-355 de 2003 Magistrado Ponente Marco Gerardo Monroy Cabra}

El problema jurídico que estudió la Corte Constitucional fue si el Artículo 98 de la Ley 769 de 2002 viola los derechos al libre desarrollo de la personalidad, al

\footnotetext{
${ }^{4}$ Texto original en inglés, traducción personal.
} 
trabajo, a la libertad de escoger profesión u oficio y a la propiedad privada. A continuación nos permitimos citar el artículo objeto de estudio:

\section{"ARTÍCULO 98. ERRADICACIÓN DE LOS VEHÍCULOS DE TRACCIÓN}

ANIMAL. En un término de un (1) año, contado a partir de la iniciación de la vigencia de la presente ley, se prohíbe el tránsito urbano en los municipios de Categoría Especial y en los municipios de primera categoría del país, de vehículos de tracción animal. A partir de esa fecha las autoridades de tránsito procederán a retirar los vehículos de tracción animal.

PARÁGRAFO $1^{\circ}$. Quedan exceptuados de la anterior medida los vehículos de tracción animal utilizados para fines turísticos, de acuerdo a las normas que expedirá al respecto el Ministerio de Transporte

PARÁGRAFO $2^{\circ}$. Las alcaldías municipales y distritales en asocio con el SENA tendrán que promover actividades alternativas y sustitutivas para los conductores de los vehículos de tracción animal."

La Corte decidió declarar los apartes subrayados inexequibles y declarar la exequibilidad del resto del artículo "bajo el entendido de que la prohibición a que se contrae la norma se debe concretar, por las autoridades municipales 0 distritales competentes, a determinadas vías y por motivos de seguridad vial, y que la misma sólo entrará a regir siempre que real y efectivamente se hayan adoptado las medidas alternativas y sustitutivas previstas en el parágrafo $2^{\circ}$ del artículo 98 de la ley antes citada, en el respectivo distrito o municipio" (Numeral Tercero, parte resolutiva de la sentencia). Adicionalmente se declaró inhibida para pronunciarse sobre el parágrafo $1^{\circ}$, por insuficiencia en la argumentación.

Las preocupaciones de esta Sentencia son básicamente dos: Por un lado, que no permite la erradicación total de estos Vehículos de Tracción Animal, por 
considerar que es competencia de las alcaldías. Por otro lado, se declaró inhibida para fallar sobre la permisibilidad de estos vehículos con fines turísticos. Sin embargo, hubiera sido muy importante un pronunciamiento sobre este parágrafo, toda vez que, en este contexto en particular, no existe diferencia entre trabajo y turismo, pues el sufrimiento y el maltrato en ambos casos sigue siendo el mismo.

\section{Sentencia C-666 de 2010 Magistrado Ponente Humberto Antonio Sierra Porto}

Esta es quizá una de las sentencias más polémicas que han existido en torno al tema animal. El problema jurídico a resolver aquí fue la excepción prevista en el artículo $7^{\circ}$ de la Ley 84 de 1989, que permite el rejoneo, el coleo, las corridas de toros, las novilladas, las corralejas, las becerradas, las tientas y las riñas de gallos; prácticas que desconocen, sin justificación legítima, el deber constitucional de protección de los animales.

La Corte realizó un análisis crítico en el que concluyó que las actividades contempladas en el artículo $7^{\circ}$ deben permitirse, pero bajo ciertos parámetros que eviten al máximo el sufrimiento de los animales. Adicionalmente precisó que el Estado de ninguna manera podría financiar este tipo de espectáculos.

Esta sentencia modulativa interpretativa del artículo $7^{\circ}$, le da prevalencia a la 'cultura' y a la 'tradición' sobre la protección a los animales, bajo el argumento de 'armonizar el deber de proteger a los animales con el principio de diversidad étnica y cultural'. Es contradictoria esa posición, toda vez que no existe ningún tipo de protección a los animales en estas prácticas arcaicas.

"Frente a la explotación de los animales para la simple recreación humana, es un mandato que ningún animal debe ser explotado para esparcimiento del hombre y que las exhibiciones de animales y los espectáculos que se 
sirvan de animales, son incompatibles con la dignidad del animal" (Trujillo, 2010, p.128)

No obstante, la lucha por su abolición total en todo el territorio nacional aún continúa.

\section{Sentencia C-283 de 2014 Magistrado Ponente Jorge Iván Palacio Palacio}

La Corte Constitucional estudia si el legislador excedió los límites normativos al aprobar el artículo 1ํ de la Ley 1638 de 2013, que consagró la prohibición del uso de animales silvestres, nativos o exóticos, en los circos de todo el territorio nacional; por desconocer una expresión cultural y artística, vulnerando los derechos al trabajo, a escoger profesión u oficio, al libre desarrollo de la personalidad, y a la libertad de empresa, además de los derechos de los menores de edad a la cultura, a la recreación y a la expresión de la opinión.

A través de varios argumentos, la Corte declaró exequible el artículo 1ำ de la Ley 1638 de 2013 por considerarlo armónico con la Constitución. A continuación me permito citar dos de los más relevantes argumentos expuestos en la parte considerativa.

"Para la Corte la prohibición establecida en el artículo $1^{\circ}$ de la Ley 1638 de 2013 armoniza plenamente con la Constitución, sin que se muestre la medida adoptada como irrazonable ni desproporcionada. El legislador, en ejercicio de su potestad de configuración normativa, está habilitado para prohibir determinadas manifestaciones culturales que impliquen un maltrato animal, lo cual se acompasa además con el carácter dinámico de la Constitución en orden a los cambios que se producen en el seno de la sociedad 


\section{$[\ldots]$}

De tal manera que la Corte halla fundamento constitucional en la determinación del Congreso al prohibir los animales silvestres en espectáculos circenses. La protección de los animales desde la perspectiva de los deberes morales y solidarios -bienestar animal-, como del comportamiento digno que los humanos están obligados a proveer respecto de otras especies -seres vivos y sintientes- en aras de la conservación del medio ambiente (C-666 de 2010), es suficiente para que este Tribunal respalde la constitucionalidad del artículo 1ํ de la Ley 1638 de 2013 por resultar conforme a los artículos $8^{\circ}, 79$ y 95, entre otros, de la Constitución."

Esta Sentencia permitió que se hiciera efectiva la protección que consagraba la Ley 1638 de 2013 a los animales silvestres. Estas prácticas eran una clara muestra de Maltrato Animal y no podían seguir justificándose bajo la sombra de las expresiones culturales y recreativas.

En este acápite podemos darnos cuenta que existe un gran avance en la protección de los animales, con fines de eliminar la tendencia especista de hoy en día, siendo esta una de las clases de discriminación más común en Colombia. "El descubrimiento de una nueva forma de discriminación, el especismo, que sería determinante del tratamiento que la sociedad brinda a los animales, y con ello, de la violencia y el maltrato institucionalizados" (Leyton, 2010, p.14). Aun así, falta mucho para lograr erradicar el especismo por completo.

\section{Derecho penal colombiano en los delitos contra los animales.}

Para determinar si el Derecho Penal es el que debe ser llamado a resolver temas como el que aquí nos atañe, parece pertinente citar el siguiente párrafo: 
"Es en general una mala jugada explicar hoy funcionalmente los fenómenos del derecho penal en acción -delito, responsabilidad y pena- por las consecuencias reales o esperadas de la pena (prevención general) y no por sus "causas sociales". Como también lo es que el Derecho, que es fruto del poder, tenga una función única o esencial la de preservar el orden de poder establecido o reforzado por las normas. Es evidente que esta visión autorreferencial del derecho es un "obstáculo al cambio social". Pues detrás de semejante visión funcionalista yace el prejuicio conservadurista o reaccionario de que todo lo que socialmente existe en un orden dado es digno de ser preservado por medio de la coacción jurídica, y el Derecho mismo ha de ser por antonomasia el objeto de esta autoprotección". (Fernández, 2014, p.5)

Lo anterior pone en evidencia un problema que hemos tenido a lo largo de los años en Colombia, que es lo que se conoce coloquialmente como 'populismo penal', que es buscar una coacción jurídica penal a cualquier acto que de alguna manera nos parece que debe ser castigado con severidad. Como lo explica el experto dominicano Eduardo Jorge Prats:

"Populismo penal "es la estrategia desplegada por actores políticos y funcionarios del sistema penal, encaminada, aparentemente, a remediar los problemas que se derivan del crimen y la inseguridad", pero que en el fondo implica una alianza demagógica para crear en la conciencia ciudadana la necesidad de aplicar medidas extremas de "mano dura" y "tolerancia cero" contra los infractores, aun en delitos de menor impacto, a sabiendas de que son respuestas eufemísticas, viscerales, basadas en sondeos no confiables, que lejos de disminuir la tasa delincuencial, la incrementan de manera incontrolable" (Prats. Como se citó en Fernández, 2012) 
En un país de conflictos como Colombia, el sistema penal no es la única vía para reducir los altos índices de criminalidad, sino una política criminal integral que involucre a todos los organismos del Estado (en lo social, económico, en la política penal) y a la sociedad misma. Lo inquietante es que el objetivo de reducción de la criminalidad en la política penal no se debe enfocar hacia un aumento de penas y una mayor represión, cuando lo más importante es la prevención general con base en la educación, y una verdadera resocialización para el condenado.

Para entender el fundamento de la creación de normas como la relativa a la protección a los animales que se materializó con la Ley 1774 de 2016 y que penalizó el maltrato animal, se debe tener en cuenta al profesor Jesús-María Silva Sánchez. Catedrático de Derecho Penal, Universidad Pompeu Fabra. Barcelona, quien afirma:

"Si el delito es un acto ineficiente, parece claro que la sociedad debe tratar de neutralizar esta clase de actos a fin de alcanzar precisamente la eficiencia. Para conseguirlo dispone, en principio, de varias líneas de actuación. Una de ellas sería la denominada prevención fáctica y consistiría en tratar de impedir por la vía de hecho la realización de tales actos ineficientes. Sin embargo, ello se muestra enormemente costoso, incluyendo entre tales costes no en último lugar el coste de la pérdida global de libertad. Algo parecido cabria apuntar a propósito de la inocuización de los sujetos que cometen tales actos (o, mejor que, dadas las circunstancias, pueden ser susceptibles de cometerlos). De ahí que el modelo establecido de modo central (sin perjuicio de su conjunción con los anteriores u otros) sea sustancialmente distinto: un modelo de prevención general por normas." (Silva, 1996, p.106)

Con esto entendemos que, en cuanto a la penalización del maltrato animal, resulta necesario tratar de neutralizar cualquier conducta que atente contra la vida 
e integridad de los animales y, con base en lo ya mencionado, no sólo en el acápite anterior sino en el acápite de marco legal y jurisprudencial, el sistema penal es parte de la búsqueda de ese fin, acompañado de otro tipo de medidas.

En una entrevista de la Pontificia Universidad Católica del Perú | PUCP, el señor Luigi Ferrajoli, Jurista italiano. Titular de la cátedra de Teoría General del Derecho de la Universidad de Roma III, dijo: "Montesquieu escribió que la civilización de un país se mide por la benignidad de sus penas. El derecho penal es más eficaz y garantista cuando sus penas son menos violentas" (Ferrajoli, 2013, párr.4)

Lo que quiere decir que entre menos altas sean las penas, más se puede prever la eficacia del Derecho Penal. Se hace mención a esto con el fin de entender lo que veremos en el siguiente acápite sobre el espíritu del legislador al determinar que el delito de Maltrato Animal es un delito excarcelable.

\section{Estudio de la Ley 1774 de 2016}

Para empezar, debemos tener presente que los bienes jurídicos tutelados que se protegen con esta Ley, son la vida y la integridad, tanto física como emocional, de los animales. Entraría en debate si la tutela de esos derechos es plena o no, de acuerdo a todo lo que hemos visto en el artículo.

En primera instancia encontramos el Artículo $\mathbf{1}^{\circ}$, con relación al objeto de la Ley donde se expone lo siguiente:

"Los animales como seres sintientes no son cosas, recibirán especial protección contra el sufrimiento y el dolor, en especial, el causado directa o indirectamente por los humanos, por lo cual en la presente ley se tipifican como punibles algunas conductas relacionadas con el maltrato a los 
animales, y se establece un procedimiento sancionatorio de carácter policivo y judicial."

Este artículo consagra la calificación de los animales como 'seres sintientes' quitándoles la categoría de 'cosas'. Es menester definir qué es la sintiencia: " $\mathrm{La}$ sintiencia es un término que proviene del inglés "sentience" y que equivale a lo que tradicionalmente se ha llamado sensibilidad o facultad de sentir. Esto es: la capacidad de experimentar sensaciones, de tener experiencias subjetivas" (Tovar. 2016, párr.2)

Esta definición sugiere que los animales son seres que, además de sentir por tener un sistema nervioso central, tienen autoconciencia, lo que es suficiente para ubicarlos dentro de la categoría de seres capaces de experimentar el mundo a través de sus sentidos, de una manera tal que pueden responder a estímulos, ya sean positivos o negativos.

De ello radica la importancia de hacer sentir a los animales como un 'alguien' y no como un 'algo', pues son seres vivos y no objetos a nuestra disposición. Es por ello que la Ley contempló, dentro de su Artículo $2^{\circ}$ una modificación al artículo 655 del Código Civil, respecto a la definición de muebles:

"Muebles son las que pueden transportarse de un lugar a otro, sea moviéndose ellas a sí mismas como los animales (que por eso se llaman semovientes), sea que sólo se muevan por una fuerza externa, como las cosas inanimadas. Exceptúense las que siendo muebles por naturaleza se reputan inmuebles por su destino, según el artículo 658.

Parágrafo. Reconózcase la calidad de seres sintientes a los animales.” 
Este artículo no eliminó la calificación de los animales dentro de los 'muebles'. Sin embargo, el parágrafo que adiciona es el que le da la categoría de 'seres sintientes'.

Aunque en un principio podríamos ver una contradicción entre los dos artículos, donde en uno dice que 'no son cosas', pero en el siguiente persiste esa calificación, el espíritu del legislador fue conservar ese artículo, para evitar un debate que generara un posible rechazo del proyecto $y$, posterior a la sanción de la ley, utilizar otro mecanismo para eliminar definitivamente la calificación de 'bienes' contemplados en los artículos del Código Civil, como la demanda por inconstitucionalidad instaurada este año 2016.

La Corte Constitucional consideró que calificar a los animales como 'bienes muebles o inmuebles por destinación', no se opone propiamente a la calificación de seres sintientes que se agregó con la Ley 1774, puesto que las dos concepciones son incluyentes entre sí. El artículo 1 al decir que 'no son cosas' lo hace con la intención de que se reconozcan como seres de especial protección, sin excluirlos del régimen de bienes. Por ello, decide declarar exequibles las normas acusadas (Corte Constitucional, Comunicado No. 37 del 31 de agosto de 2016).

Así las cosas, podemos darnos cuenta que la Corte Constitucional no les quita la categoría de objetos, permitiendo así la libre disposición para ejercer sobre ellos la propiedad, posesión y tenencia, siempre y cuando sea bajo ciertos parámetros mínimos de respeto consagrados en la Ley 1774.

Puede considerarse un error del legislador el haber consagrado dicha contradicción, incluso bajo la premisa de que lo hizo con intencionalidad, como también existe un desacierto de la Corte, al no eliminar la categoría de bienes, o al menos optar por una exequibilidad condicionada de los artículos, toda vez que se sigue dando vía para que se utilicen como bienes al servicio del hombre, 
restándole importancia a la categoría de seres sintientes, como expresan los Magistrados María Victoria Calle y Alberto Rojas Ríos en sus salvamentos de voto:

"No bastaba con decir que los animales tienen la doble condición de cosas y seres sintientes para resolver el problema planteado por la Sala, pues si bien la función social y ecológica de la propiedad, o el mandato de constitución verde pueden dar lugar a normas de protección adecuadas a bienes de relevancia ambiental, no tienen la misma fuerza para proteger a los seres capaces de sentir. Curiosamente, la decisión de la mayoría (i) se opone a toda evidencia, al considerar que las cosas pueden sentir, (ii) afirma que cuando el legislador dice que los animales no son cosas, no fue eso lo que quiso decir, (iii) plantea que las definiciones no tienen consecuencias jurídicas, al tiempo que acepta que la Corte ha controlado el lenguaje, en diversas ocasiones y escenarios constitucionales (es cierto que se trata de un control excepcional, pero no de una decisión aislada). Es evidente que la definición de los animales como cosas se opone a los deberes del ser humano hacia los animales no humanos; es claro que las cosas no sienten, en el nivel actual de conocimiento; y (iii) está demostrado que esa clasificación avala todo tipo de tratos indignos, como lo ha aceptado esta Corte en otras oportunidades (por ejemplo, al avalar la prohibición de incluir animales no humanos en espectáculos circenses)." (Salvamentos de voto del Comunicado No. 37)

Ahora bien, el Artículo $3^{\circ}$ consagra los principios básicos que deben tenerse en cuenta en torno a la relación con el trato a los animales en torno a su bienestar y seguridad, de la siguiente manera:

“a) Protección al animal. El trato a los animales se basa en el respeto, la solidaridad, la compasión, la ética, la justicia, el cuidado, la prevención del 
sufrimiento, la erradicación del cautiverio y el abandono, así como de cualquier forma de abuso, maltrato, violencia, y trato cruel;

b) Bienestar animal. En el cuidado de los animales, el responsable o tenedor de ellos asegurará como mínimo:

1. Que no sufran hambre ni sed,

2. Que no sufran injustificadamente malestar físico ni dolor;

3. Que no les sean provocadas enfermedades por negligencia o descuido:

4. Que no sean sometidos a condiciones de miedo ni estrés;

5. Que puedan manifestar su comportamiento natural;

c) Solidaridad social. El Estado, la sociedad y sus miembros tienen la obligación de asistir y proteger a los animales con acciones diligentes ante situaciones que pongan en peligro su vida, su salud o su integridad física.

Asimismo, tienen la responsabilidad de tomar parte activa en la prevención y eliminación del maltrato, crueldad y violencia contra los animales; también es su deber abstenerse de cualquier acto injustificado de violencia o maltrato contra estos y denunciar aquellos infractores de las conductas señaladas de los que se tenga conocimiento."

El primer principio es la Protección al Animal que abarca deberes para con los animales. Este consagra el Respeto del latín 'respectus', que significa atención o consideración (Pérez y Merino, 2008); la Solidaridad, como sinónimo de "apoyo o adhesión circunstancial a una causa o al interés de otros" ("Significado de Solidaridad", s.f); la Compasión de latín 'cumpassio' que significa acompañar o sentir piedad ("Definición ABC", s.f); la Ética del latín 'ethǐcus' ("Significado de Ética", s.f) que ayuda a discernir entre el bien y el mal; la Justicia del latín 'iustitǐa', entendida "como lo que debe hacerse de acuerdo a lo razonable, lo equitativo o lo 
indicado por el derecho" (Pérez y Merino, 2008); el Cuidado, como el deber que se tiene con los seres más débiles de "tratar de incrementar su bienestar y evitar que sufra algún perjuicio" (Pérez y Gardey, 2010); la prevención del sufrimiento, con actos que permitan priorizar el bienestar animal; la erradicación del cautiverio y el abandono, por ir en contra de una vida digna para los animales; así como de cualquier forma de abuso, maltrato, violencia, y trato cruel.

El segundo principio es el Bienestar Animal que consagra parámetros mínimos para que un animal pueda estar en buenas y dignas condiciones proporcionadas por las condiciones de vida que pueden brindan los seres humanos. "Criterio fundamental para el bienestar es la salud animal; no hay bienestar sin salud. Sin embargo, el bienestar puede asegurar la salud" (Capó, 2005, p.11).

El tercer principio de Solidaridad Social abarca ese deber de todos de proteger a los animales, e incluye la protección que el Estado debe brindarles, consagrando también el deber de actuar ante cualquier situación que ponga en peligro la vida e integridad de cualquier animal, con la intervención y sobre todo con la denuncia. En otras palabras, no sólo es suficiente con cumplir con ese deber de protección, sino que se debe actuar frente a cualquier acto de violencia contra los animales.

El Artículo $4^{\circ}$, que modifica el artículo 10 de la Ley 84 de 1989, buscó incrementar las multas que contenía la anterior ley, toda vez que, como ya se mencionó, las contenidas eran completamente irrisorias, dejándolas de cinco (5) a cincuenta (50) salarios mínimos legales mensuales vigentes, por lesiones que no causaren muerte $\mathrm{o}$ afectaciones graves a la salud o integridad física de los animales.

El Artículo $5^{\circ}$ es el principal objeto de nuestro estudio, toda vez que con éste se adiciona al Código Penal el Título XI-A 'De los delitos contra los animales' 
Capítulo Único 'Delitos contra la vida, la integridad física y emocional de los animales'. Artículos 339A y 339B. Analicemos primero el Artículo 339A:

"El que, por cualquier medio o procedimiento maltrate a un animal doméstico, amansado, silvestre vertebrado o exótico vertebrado, causándole la muerte o lesiones que menoscaben gravemente su salud o integridad física, incurrirá en pena de prisión de doce (12) a treinta y seis (36) meses, e inhabilidad especial de uno (1) a tres (3) años para el ejercicio de profesión, oficio, comercio o tenencia que tenga relación con los animales y multa de cinco (5) a sesenta (60) salarios mínimos mensuales legales vigentes."

En este artículo se establecen dos maneras de Maltrato Animal: La primera es causar la 'muerte', definida esta como "la cesación total de la actividad de todas y cada una de las células de los tejidos, que se va dando gradualmente y es seguida por el proceso de descomposición" (Aguilera, 1990, p.20). La segunda son las lesiones que menoscaban 'gravemente' la salud o integridad física, es decir, que afecte, tanto física como emocionalmente a un animal.

Este podría verse como el primer delito en que directamente los animales son los objetos materiales de la acción, con miras a buscar su protección como seres sintientes, sin poner de por medio el comercio o el medio ambiente.

Este tipo penal se clasifica como de resultado objetivo porque se requiere que se produzcan lesiones o la muerte del animal; es de lesión porque se requiere que se afecte efectivamente el bien jurídico tutelado; es de conducta instantánea porque se materializa por la acción u omisión en el momento que se realiza por el sujeto agente; y es pluriofensivo porque ofende al Estado a cuyo cargo está la protección de los animales, e incluso a los particulares en su patrimonio económico cuando son propietarios de los mismos. 
Es un tipo penal en blanco que para efecto de su comprensión debemos remitirnos a normas de naturaleza extrapenal que definen algunos conceptos en forma precisa, posición compartida con el Abogado Sergio Manzano, quien en el Conversatorio denominado ¿¿Qué sigue a la sanción de la ley que penaliza el Maltrato Animal en Colombia?', manifestó que éste es un tipo penal en blanco propio, pues la norma no precisa lo que significa 'gravedad' de la afectación en la salud, lo que requerirá necesariamente remisión de otras normas, principalmente la Ley 84 de 1989. (Manzano, 2016)

Como características de este tipo penal, encontramos que el bien jurídico tutelado es vida e integridad física y emocional de los animales. El verbo rector es 'maltratar', que significa para efectos de este tipo penal, causar daño físico o moral a un animal mediante lesiones o la muerte.

El objeto material es de naturaleza real porque los animales siguen siendo considerados como bienes muebles. La conducta de maltrato debe recaer sobre un animal, sea este doméstico, amansado, silvestre vertebrado o exótico vertebrado. El animal doméstico es aquel que se cría y convive con el ser humano a diferencia del salvaje. El amansado es un animal que ha sido domado en su carácter violento, apaciguado, que se ha vuelto manso por la intervención del hombre. Se denominan animales silvestres, bravíos o salvajes aquellos vertebrados que viven libres e independientes del hombre (Artículo 29 de la Ley 84 de 1989). Los animales exóticos vertebrados son especies foráneas, que se encuentran por fuera de la distribución de la naturaleza, cuyo origen natural ha tenido lugar en otra parte del mundo y que han sido trasladadas a otro sitio.

El Sujeto Activo es indeterminado, es decir, cualquier persona puede cometer el delito, no se exige una calidad especial del actor. En relación con los animales silvestres y exóticos el Sujeto Pasivo es el Estado que es el titular del bien jurídico 
cuya protección está obligado a ejercer sobre la fauna silvestre; en relación con los animales domésticos y amansados el titular del bien jurídico es el propietario de dichos animales y de no tenerlo es el Estado como protector de los mismos.

Es un tipo penal netamente doloso, es decir no admite modalidad de culpa; contempla una pena mínima de 12 meses y máxima de 36 meses de prisión, es decir, es un delito excarcelable; y contempla multas hasta 60 SMLMV, que a hoy 2016, serían unos Cuarenta y Un Millones Trescientos Sesenta y Siete Mil Trescientos Pesos $(\$ 41.367 .300,00)$ aproximadamente, e inhabilidades para ejercer alguna profesión u oficio relacionado con los animales.

Otro punto importante que requiere atención es que es un tipo penal doloso únicamente, lo que podría presentar un vacío en la normatividad, pues en el evento en que se presente este delito por un hecho culposo, debido a una violación al deber objetivo de cuidado de los animales, será completamente atípico, es decir, la conducta no será punible y por ende generará límites a la actuación tanto policial como judicial.

Ahora bien, la intención del legislador aquí fue imponer multas altas que condicionaran la pena excarcelable, teniendo en cuenta la situación compleja que el país enfrenta hoy en día con el sistema penitenciario y carcelario. Aquí podemos ver como la ley evita caer en el 'populismo penal' porque, si bien como ya vimos el recurrir a la vía penal por cualquier problema social puede ser más perjudicial que benéfico, aquí no hay esa afectación, ya que no se pretende propiamente la privación de la libertad sino, a través del sistema punitivo, generar la suficiente conciencia de que maltratar es un hecho reprochable por la sociedad y, así mismo, un acto completamente injusto.

Hay que tener presente que "La pena es la sanción impuesta al delincuente, $o$ sea, la consecuencia desfavorable que se sigue para una persona a quien se 
imputa un acto penalmente antijurídico. Su finalidad no es solo retributiva, sino también preventiva, protectora y resocializadora" (Noguera, 2007, p. 186). (Subrayado fuera de texto original)

Ahora analizaremos las circunstancias de agravación punitiva que se consagraron en el Artículo 339B:

“Las penas contempladas en el artículo anterior se aumentarán de la mitad a tres cuartas partes, si la conducta se cometiere:

a) Con sevicia;

b) Cuando una o varias de las conductas mencionadas se perpetren en vía o sitio público;

c) Valiéndose de inimputables o de menores de edad o en presencia de aquellos;

d) Cuando se cometan actos sexuales con los animales;

e) Cuando alguno de los delitos previstos en los artículos anteriores se cometiere por servidor público o quien ejerza funciones públicas.

Parágrafo $1^{\circ}$. Quedan exceptuadas de las penas previstas en esta ley, las prácticas, en el marco de las normas vigentes, de buen manejo de los animales que tengan como objetivo el cuidado, reproducción, cría, adiestramiento, mantenimiento; las de beneficio y procesamiento relacionadas con la producción de alimentos; y las actividades de entrenamiento para competencias legalmente aceptadas.

Parágrafo $2^{\circ}$. Quienes adelanten acciones de salubridad pública tendientes a controlar brotes epidémicos, o transmisión de enfermedades zoonóticas, no serán objeto de las penas previstas en la presente ley. 
Parágrafo $3^{\circ}$. Quienes adelanten las conductas descritas en el artículo $7^{\circ}$ de la Ley 84 de 1989 no serán objeto de las penas previstas en la presente ley"

Analicemos con detenimiento los agravantes que aquí se contemplan:

Sevicia, que "consiste en los malos tratamientos realizados con crueldad y espíritu de hacer sufrir. Se requieren, pues, dos elementos: uno físico, los malos tratos; otro psicológico, la intención despiadada de hacer daño". (Garrone. 2005. p. 397)

* Cuando se realicen en vía pública, por la existencia de una impresión social, debe ser considerado como algo mayor.

* Cuando se utilicen inimputables, o menores de edad, o en presencia de ellos; donde aquí debemos definir Imputabilidad como:

"Capacidad psíquica de una persona de comprender la antijuridicidad de su conducta y de no adecuar la misma a esa comprensión. Pero algunas veces un sujeto deja de ser imputable por las llamadas Causas De Inimputabilidad. Las causas de inimputabilidad son aquellas situaciones que, si bien la conducta es típica y antijurídica, hacen que no sea posible atribuir el acto realizado al sujeto por concurrir en él: Enfermedad mental, Grave Insuficiencia de la Inteligencia, Grave Perturbación de la conciencia o Ser menor de 16 años" (Machicado. 2013) (Subrayado fuera de texto para aclarar que en Colombia para que un menor sea considerado inimputable debe ser menor de 14 años)

Actos sexuales con animales: conocida como 'Zoofilia', siendo esta la atracción sexual hacia algún animal o "trastorno psicosexual en el que se consigue excitación y satisfacción sexual mediante fantasías o conductas en las que hay 
actos sexuales con animales" (Enciclopedia Salud. 2016). Este agravante lo quiso agregar el legislador por estudios que evidencian que personas que comenten este tipo de actos, son los que posteriormente se ven involucrados en delitos sexuales con menores de edad o incluso con cualquier persona.

* Cuando sea cometido por un servidor público, por su calidad de tal, es decir, se habla de un agravante por sujeto activo calificado. Este agravante lo contempló el legislador porque un servidor público es una persona que debe dar ejemplo por el cargo que éste presta, por lo tanto, es algo que genera más reprochabilidad.

Dentro de estos agravantes, se considera que al legislador omitió incluir el que se cometiera contra animales en peligro de extinción. Es evidente que ellos merecen un trato exclusivo por la finalidad de conservación. También debería existir un agravante para la persona que cometiera la conducta contra un animal perteneciente a la estrecha comunidad de vida, es decir, que esté bajo su propiedad o tenencia.

Ahora bien, este artículo además contempla 3 parágrafos que contienen unas excepciones con el fin de no entorpecer actividades como la industria cárnica (Parágrafo 1), la protección del bien común por afectaciones en la salubridad (Parágrafo 2) y las tan debatidas actividades de espectáculos contemplados en el artículo 7 de la Ley 84 de 1989, del cual ya hablamos en el acápite de jurisprudencia del presente artículo (Parágrafo 3).

La razón por la cual el legislador agregó ese parágrafo 3, fue con evitar un posible rechazo del proyecto, toda vez que estas prácticas tienen protección constitucional. Sin embargo, como se mencionó, la tarea para erradicar estas prácticas continúa. 
En el Artículo $6^{\circ}$, se asignó una nueva atribución a los Jueces Penales Municipales para conocer los casos del delito contra los animales.

En los Artículos $7^{\circ}$ y $8^{\circ}$ se encuentra la competencia y los procedimientos administrativos que deberán llevarse a cabo si se está en presencia de Maltrato Animal, bajo las condiciones establecidas en el Artículo $4^{\circ}$ de esta Ley.

De acá parece importante mencionar el parágrafo del Artículo $7^{\circ}$, donde se consagra que el destino de los dineros recaudados por conceptos de multas, irán dirigidos a campañas de sensibilización y educación ciudadana, y constitución de fondos para protección animal destinados a las diferentes organizaciones existentes.

Podría decirse que en este parágrafo se consagra el espíritu de esta ley, y por ende la razón del incremento de las multas. La concientización de las personas es aún más fundamental que cualquier otro tipo de coerción, si la pretensión es que este tipo de actos no se sigan cometiendo. Las ayudas económicas, derivadas de estas multas, hacen entender la función social de la pena de manera absoluta.

El Artículo $9^{\circ}$ contempla el aumento de las multas que existían antes en la Ley 84 de 1989, donde las absurdas multas oscilaban entre Siete Mil Quinientos Pesos (\$7.500) y Cien Mil Pesos $(\$ 100.000)$. Por eso se contemplaron en Salarios Mínimos Legales Mensuales Vigentes, para que no quedaran devaluadas con el paso del tiempo. Con el Salario Mínimo de este año 2016, estaríamos hablando de una multa mínima de aproximadamente Cuatro Millones Ochocientos Veintiséis Mil Ciento Setenta y Ocho Pesos (\$4.826.178) y un máximo de aproximadamente Treinta y Cuatro Millones Cuatrocientos Setenta Dos Mil Setecientos Pesos (\$34.472.700). 
El Artículo $10^{\circ}$ agrega una facultad del Ministerio de Ambiente para desarrollo de campañas pedagógicas con el fin de orientar a las personas en las mejores formas de relación con los animales.

Estas campañas son importantes para el trato y cuidado de cada especie animal, por las diversas características que cada tipo presenta. Al tener claridad sobre esas características, se les podrá brindar el mayor bienestar posible, tanto a los animales propios, como a los animales ajenos e incluso a los que se encuentran en condición de abandono.

Para muchos esta ley fue un logro trascendental al pasar de una casi nula protección a una protección bajo el sistema represivo más fuerte que existe en nuestro país. No obstante, no todo el mundo piensa de la misma manera, hay quienes creen que la protección a los animales no merece ser contemplada por la normatividad penal, por creer que al sumar un delito más a los ya existentes, se generará más congestión en la rama judicial.

Otro punto a considerar es que, en el afán de promulgar una ley que protegiera a los animales, se dejaron varios puntos sueltos que más adelante podrán generar confusiones e incluso situaciones de impunidad. A continuación me permito nombrar y resumir algunos de los puntos que seguramente la ley no contempló o no lo hizo de manera completa:

Primero, si se da el secuestro de un animal, éste no podría contemplarse como delito en ese sentido y tendría que enmarcarse en el tipo penal de 'hurto', que es para protección de 'bienes', lo que automáticamente genera una contradicción sobre cómo actuar y denunciar, o peor aún, pensarse que no se configura ningún delito, situación que automáticamente generaría impunidad. 
Segundo, se dejaron de lado las regulaciones, si es que no la contemplación de prohibición, a establecimientos de comercio dedicados a compra-venta de animales domésticos, pues en la actualidad no se cumplen los controles establecidos.

Tercero, no se contempló el delito bajo la modalidad culposa y por este motivo pueden existir varios delitos que queden impunes, pues el 'deber objetivo de cuidado' debe tenerse frente a todos los seres.

Cuarto, ausencia de algunos posibles agravantes, como se mencionó anteriormente.

Quinto, el consagrar de manera clara si las omisiones, como 'omisión de socorro' u 'omisión de denuncia', pueden hacerse extensivas para este tipo penal Maltrato Animal. Entre otras más que podemos ir encontrando a medida que se presentan los casos.

Como se ha manifestado en reiteradas oportunidades, la finalidad no es congestionar el sistema judicial y mucho menos enviar a las cárceles hacinadas a los que cometan el delito de Maltrato Animal, la pretensión es y siempre ha sido que se les reconozca a los delitos contra los animales una importancia similar a la de los delitos contra las personas, generando conciencia, para así evitar al máximo que sigan estos atroces actos en contra de estos seres.

\section{Primeros casos de investigaciones penales por maltrato animal}

A continuación nos permitimos hacer una pequeña selección de los primeros casos existentes posteriores a la ley, cada uno con diferentes clases de víctimas, con el fin de mostrar la actuación, hasta el momento, del ordenamiento jurídico colombiano y de las autoridades policiales. Se aclara que hasta el momento no se 
conoce ninguna decisión en ninguno de los casos que existen y la información aquí consagrada fue recopilada gracias al conversatorio ‘¿Qué sigue a la sanción de la ley que penaliza el Maltrato Animal en Colombia? realizado por AnimaNaturalis Colombia en el mes de febrero del 2016, y a los diferentes medios de comunicación.

\section{* CASO 1 (Víctima: Animal protegido)}

En el mes de enero de 2016 se presentó el caso del asesinato de un oso de anteojos (especie protegida) en el Parque Natural Chingaza (Cundinamarca). "Expertos en balística aseguraron que el oso recibió dos impactos de arma de fuego y que uno de los tiros lo hicieron a una distancia no superior a los 100 metros y el otro, a corta distancia. Es decir que el oso fue rematado estando herido". (El Tiempo. 2016)

Se capturaron los implicados y el fiscal encargado imputo cargos. Sin embargo el Juez de Control de Garantías deja en libertad a los implicados por no representar peligro para la sociedad.

Este es un caso con una víctima catalogada como 'especie protegida', por ser un animal en peligro de extinción. La Ley 1774 no contempla agravantes relacionados con esta condición y, como se mencionó anteriormente, sería importante que éste estuviese incluido para casos como el presente. No obstante, aquí sí podría contemplarse el agravante de 'sevicia', de acuerdo a lo que determinaron los expertos en balística.

\section{CASO 2 (Víctima: Animal silvestre)}

A los pocos días del caso anterior, se presentó este segundo caso. En el Valle del Cauca un perro de monte fue torturado hasta la muerte. El caso se conoció 
porque los presuntos implicados publicaron fotos en Redes Sociales. Al instante, más allá del rechazo social que generaron las publicaciones, se entabló la denuncia respectiva. Hasta el momento, lo único que se conoce del caso fue el despedido laborar de uno de los sujetos que presuntamente cometió el delito.

Aquí podemos ver una conducta típica del delito de Maltrato Animal agravado por sevicia y se podría incuso pensar en una medida de seguridad por considerar a estas personas como peligro para la sociedad.

\section{* CASO 3 (Delito cometido con más de un agravante)}

El 04 de febrero de 2016, un ciudadano de 19 años asesina a un perro con arma corto-punzante en el corregimiento de La Boquilla - Bolívar. El hombre es capturado en flagrancia y se demuestra que el delito fue cometido en vía pública y en presencia de menores de edad.

Hasta el momento solo se llevó a cabo la legalización de captura e imputación de cargos por el delito de Maltrato Animal. Actualmente el victimario se encuentra en libertad.

En este caso podemos darnos cuenta que el fiscal, aparentemente, no contempló los tres agravantes que rodean el caso, como lo son la sevicia, el haber sido cometido en vía pública y en presencia de menores de edad.

\section{* CASO 4 (Víctima: Animal Doméstico)}

Este caso se presentó el 6 de febrero de 2016 en Cúcuta, Norte de Santander. Un canino de raza Pitbull muere atacado a patadas por su dueño, por no querer salir de abajo de la cama. El hecho fue denunciado por los vecinos del sector y la policía procedió a la captura del hombre de 24 años, dejándolo a manos de la 
Fiscalía. En este caso tampoco hay duda de que se configura el delito de Maltrato Animal, agravado por la Sevicia.

Se trae este caso a colación por ser un caso en el que podría configurarse el agravante que se propone en este artículo, por pertenecer a una 'estrecha comunidad de vida', toda vez que quién comete el hecho delictivo es 'dueño' de la víctima.

Como se puede observar, la Ley 1774 ha sido una buena herramienta para poder denunciar los varios casos de Maltrato Animal que se presentan en el país. Sin embargo no puede dejarse de lado que es una ley muy nueva que hasta ahora está conociéndose, tanto por parte de la ciudadanía como por parte de los diferentes funcionarios públicos, razón por la cual los procesos se tornan un poco sosegados.

No debe perderse de vista que una de las finalidades de penalizar el Maltrato Animal es la prevención general, concientizando a las personas que éste ya es un delito en Colombia que puede llegar a ser tan importante como un delito contra la vida e integridad de una persona. Razón suficiente para que este tipo de situaciones no sigan quedando en la impunidad, ni sigan siendo enmarcados dentro del tipo penal consagrado en el artículo 265 del Código Penal 'Daño contra bien ajeno'.

Por tal motivo, se espera una mayor difusión de la Ley para que a medida que pase el tiempo se logre consolidar y disminuyan los casos que, hasta el momento, a casi un año de su sanción, sigue siendo una cifra preocupante. 


\section{* CONCLUSIONES}

Es una necesidad imperiosa que las leyes vayan cambiando a medida que los tiempos pasan, es parte del dinamismo normal del derecho. Es por ello que la insuficiencia legal existente en torno al Maltrato Animal, fue el impulso que llevó a la creación de una ley sancionatoria, para aquellos que transgredieran la esfera de protección animal. A través de las distintas ramas del poder público se debe seguir persistiendo para alcanzar una protección plena de los animales y así mismo llegar a pensar ya en los 'Derechos de los Animales'.

La Ley 1774 de 2016 es sin duda uno de los más grandes avances que se han tenido en materia de protección a los animales en Colombia, pues antes de esta ley las sanciones eran meramente administrativas y ahora pasaron a ser conocimiento del ámbito penal.

A la respuesta de nuestro problema jurídico podemos contestar que el derecho penal colombiano protege a los animales a través de la penalización del Maltrato (muerte o graves lesiones físicas y emocionales). El determinar penas excarcelables y multas más altas, con destinos a entidades encargadas de la protección y bienestar animal, es lo que le otorga éxito a esta ley, permitiendo contradecir a los que creen que se está cayendo en el 'populismo penal', pues la finalidad principal no es la privación de la libertad, y no lo es no porque no sean estas conductas lo suficientemente graves para contemplarla, sinopor la sencilla razón de que se debe pensar en un conjunto de posibilidades al crear una ley tan importante, como la situación penitenciaria y carcelaria del país que simplemente no permitiría pensar en unas penas más altas a las contempladas.

No debemos dejar de lado que aún existen muchos vacíos, como los mencionados en el acápite tercero del presente artículo, que eventualmente deben 
ser llenados. Un paso importante para que éstos sean subsanados es que no se descarte la opción de elevar a rango constitucional, de manera directa, la protección de los animales y terminar de labrar el camino para algún día reconocerlos plenamente como seres sujetos de derechos.

Claro está que no será fácil y no todos estarán de acuerdo en tenerlo como una prioridad. Es un debate arduo, pero que debe continuar para que cada día la conciencia sea mayor, pues "la falta de una cultura de respeto hacia los animales, es la fuente más firme de especismo" (Cárdenas y Fajardo, 2007, p.259) y la meta siempre debe ser la erradicación de éste a través de la concientización.

Para finalizar, otra de las propuestas que se pretende consagrar en el presente artículo reflexivo, es la implementación de la Cátedra del Derecho Animal en las Universidades de Colombia. Vemos que es ya prácticamente una necesidad para los juristas que se conozca y estudie este tema a profundidad, de cara al nuevo delito y a los avances en el tema. 


\section{REFERENCIAS BIBLIOGRÁFICAS}

* Cubides, A. (02 de octubre de 2014). Derechos de los animales: ¿una posibilidad jurídica? Ámbito Jurídico. Recuperado de https://www.ambitojuridico.com

* Morales, K. (2003). Necesidad de reformar la sanción penal en contra del maltrato de los animales. Tesis de Pregrado. Recuperado de: http://biblioteca.usac.edu.gt/tesis/04/04_11256.pdf

* Garner, R. (2005). The political theory of animal rights. Manchester. Inglaterra: Manchester University Press

* Krauthausen, C (18 de mayo de 2002). Alemania da rango constitucional a la protección de los animales. El País. Recuperado de http://www.elpais.com/

* Cárdenas, A. y Fajardo, R. (2007). El Derecho de los Animales. Bogotá D.C., Colombia: Legis Editores S.A

* Martínez, L. (s.f) No hay razas de perro peligrosas, sino dueños peligrosos. Revista Muy Interesante. Recuperado de: http://www.muyinteresante.es

* Tamara L. (Ed.). (1999). The Rights of Animals. San Diego, Estados Unidos: Editorial GreenhavenPress, Inc

* Casey, R.A., Loftus, B., Bolster, C., Richards, G.J. y Blackwell, E.J. (2014). Human directed aggression in domestic dogs (Canis familiaris): Occurrence in different contexts and risk factors. Applied Animal Behaviour Science, (152), 52-63. doi: 10.1016/j.applanim.2013.12.003

* Trujillo, J. (2010) Legislación en defensa de los animales. Corporación Universitaria Republicana. Bogotá D.C. Recuperado de: http://www.unilibre.edu.co/verbaiuris/24/legislacion-en-defensa-de-losanimales.pdf

Leyton, F. (Mayo, 2010). Literatura básica en torno al especismo y los derechos animales. Revista de Bioética y Derecho. Recuperado de http://revistes.ub.edu/index.php/RBD/article/view/7710/9613 
* Fernández, J. (2014). Concepto y Límites del Derecho Penal. Bogotá D.C., Colombia: Temis.

* Fernández, W. (2 de marzo de 2012). Populismo Punitivo. Ámbito Jurídico. Recuperado de https://www.ambitojuridico.com

* Silva, J.M. (1996). Eficiencia y Derecho Penal. Anuario de derecho penal y ciencias penales, 49(1), 93-127. Recuperado de: https://dialnet.unirioja.es/ejemplar/5226

* Ferrajoli, L. (9 de mayo de 2013). El derecho penal es más eficaz cuando sus penas son menos violentas. Recuperado de: http://puntoedu.pucp.edu.pe/entrevistas/garantismo-y-derecho-penal/

* Tovar, L. (2016). Sintiencia: la capacidad de sentir. PrensAnimalista. Recuperado de: http://www.prensanimalista.cl/

* Capó, M. (2005). Aplicación de la bioética al bienestar y al derecho de los animales. Madrid. España: Complutense.

* Aguilera, P. (1990). En la frontera vida-muerte: problemas bioéticos. Santiago de Chile. Chile: Editorial Universitaria S.A

* Noguera, L. (2007). Introducción General al Derecho. Bogotá D.C., Colombia: Distribuidora y Librería Universitaria.

* Valencia, M. y Chigüiro Estudio (Productores). (2016). ¿Qué sigue a la sanción de la ley que penaliza el Maltrato Animal en Colombia? [Youtube]. De: https://www.youtube.com/watch?v=DENJYrgjsec

* Garrone, J. (2005). Diccionario Jurídico. Buenos Aires, Argentina: LexisNexis

* Machicado, J. (2013) ¿Qué es la imputabilidad? [Mensaje en un blog]. Recuperado de: http://jorgemachicado.blogspot.com/2013/05/imp.html

* Enciclopedia salud. (2016). [Versión Electrónica] De: http://www.enciclopediasalud.com/

* El Tiempo. (25 de enero de 2016). Repudio nacional por caza y muerte de un oso de anteojos. El Tiempo. Recuperado de: http://www.eltiempo.com/

* Pérez, J. y Merino, M (2008) Definición.de. Recuperado de: http://definicion.de/respeto/ 
* Significado de Solidaridad (s.f) Significados. Recuperado de: https://www.significados.com/solidaridad/

* Definición de Compasión (s.f) Definición ABC. Recuperado de: http://www.definicionabc.com

* Significado de Ética (s.f) Significados. Recuperado de: https://www.significados.com /etica/

* Pérez, J. y Merino, M (2008) Definición.de. Recuperado de: http://definicion.de/justicia/

* Pérez, J. y Gardey, A (2010) Definición.de. Recuperado de: http://definicion.de/cuidado/ 